\title{
Patient-Centered Medical Home in chronic obstructive pulmonary disease
}

\author{
This article was published in the following Dove Press journal: \\ Journal of Multidisciplinary Healthcare \\ 21 October 2011 \\ Number of times this article has been viewed
}

\author{
Gabriel Ortiz' \\ Len Fromer ${ }^{2}$ \\ 'Pediatric Pulmonary Services, El Paso, \\ TX; ${ }^{2}$ Department of Family Medicine, \\ David Geffen School of Medicine, \\ UCLA, Los Angeles, CA, USA
}

\begin{abstract}
Chronic obstructive pulmonary disease (COPD) is a progressive and debilitating but preventable and treatable disease characterized by cough, phlegm, dyspnea, and fixed or incompletely reversible airway obstruction. Most patients with COPD rely on primary care practices for COPD management. Unfortunately, only about 55\% of US outpatients with COPD receive all guideline-recommended care. Proactive and consistent primary care for COPD, as for many other chronic diseases, can reduce hospitalizations. Optimal chronic disease management requires focusing on maintenance rather than merely acute rescue. The Patient-Centered Medical Home (PCMH), which implements the chronic care model, is a promising framework for primary care transformation. This review presents core $\mathrm{PCMH}$ concepts and proposes multidisciplinary team-based PCMH care strategies for COPD.
\end{abstract}

Keywords: Patient-Centered Medical Home, chronic care model, chronic obstructive pulmonary disease, patient education, physician assistants, nurse practitioners

\section{Introduction}

Chronic obstructive pulmonary disease (COPD) is a progressive and debilitating but preventable and treatable disease characterized by cough, phlegm, dyspnea, and fixed or incompletely reversible airway obstruction. ${ }^{1}$ Only $55 \%$ of US outpatients with COPD and $33 \%$ of COPD inpatients receive all guideline-recommended care. ${ }^{2}$ Gaps in care for COPD and other chronic diseases do not merely result from underfunding. Regions of the US costing Medicare the most do not necessarily do better on care quality indicators than less costly, but otherwise similar, regions. ${ }^{3,4}$ Focus on reimbursable procedures rather than evidence-based primary care is often the culprit. ${ }^{3}$ Primary management of chronic diseases requires more integrative "thinking" than technological "doing", 5 and is too often underpaid and undervalued relative to its importance to patients. ${ }^{3}$

Superficial remedies, ie, "just trying harder" and primary care gatekeeping, will not improve patient outcomes ${ }^{6}$ or cure cost disparities. ${ }^{7}$ Redesign of practice is needed to facilitate proactive primary care of chronic conditions and integrated and accountable delivery of specialty and inpatient services. ${ }^{8}$ The Patient-Centered Medical Home $(\mathrm{PCMH})$ is a promising framework for this practice transformation. Multiple professions, including physicians, physician assistants, and nurse practitioners, as well as nurses, medical assistants, and registered respiratory therapists, all have roles to play in team-based PCMH care for COPD.

The PCMH implements, refines, and extends the principles of its predecessor, the chronic care model (Figure 1). ${ }^{9}$ Multidisciplinary team care focused on maintaining wellness, rather than merely reacting to acute illness, is central to the chronic care model
Pediatric Pulmonary Services, American Academy of Physician Assistants Liaison to the American Academy of Allergy, Asthma, and Immunology, I20 I E Schuster, Suite 5B, El Paso, TX, USA

Tel +I 9155443229

Email aapaaai99@yahoo.com 
A

The chronic care model



Improved outcomes

Developed by The MacColl Institute ® ACP-ASIM Journals and Books

B

\section{Content of PPC-PCMH-Wagner CCM}

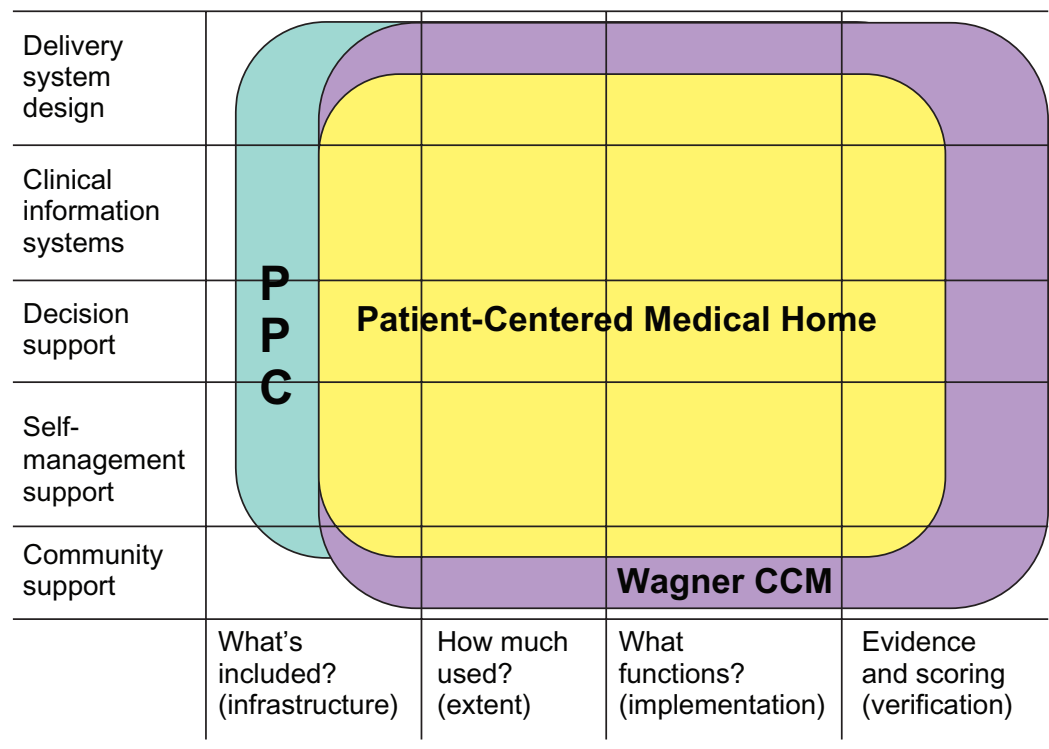

Physician Practice Connections-Patient-Centered Medical Home (PPC-PCMH)

Figure I The chronic care model (CCM).

Notes: The Improving Chronic Illness Care program is supported by The Robert Wood Johnson Foundation, with direction and technical assistance provided by Group Health Cooperative of Puget Sound's MacColl Institute for Healthcare Innovation, and its relationship to the Patient-Centered Medical Home. (A) Copyright $\odot 1998$. Effective Clinical Practice. Reproduced with permission from Wagner EH. Chronic disease management: what will it take to improve care for chronic illness? Eff Clin Pract. 1998; I (I):2-4.9 (B) Reproduced with permission from National Committee for Quality Assurance.

and the PCMH. ${ }^{10,11}$ Because providing all current guidelinerecommended care to patients in an average practice would require nearly three full-time primary care providers, practices need to reorient to a team approach in which physician assistants and/or nurse practitioners do most first-contact care, and physicians lead the care team and manage complex patients. ${ }^{12}$ 
PCMH demonstration projects have found expansion of multidisciplinary allied-health roles indispensable for a sustainable PCMH transition. ${ }^{13}$ This shift from physician-centered to a team approach may be the greatest personal challenge a physician faces in the PCMH transition. ${ }^{14}$

Accountable care organizations can be considered integrated "medical villages" for the $\mathrm{PCMH}$, coordinating evidence-based and cost-effective specialty and inpatient services with primary care. ${ }^{8,15}$ Proactiveness, quality, and continuity of primary care for COPD, as for other "ambulatory care-sensitive" chronic diseases, are crucial in reducing inpatient utilization. ${ }^{16}$ Thus, COPD care stands to benefit from the PCMH-accountable care organization approach. This review will present core PCMH concepts and discuss multidisciplinary team-based PCMH care strategies for COPD.

\section{PCMH components, certification, and compensation}

The American Academy of Family Practice model of the PCMH is shown in Figure 2. PCMH principles were jointly developed by the American Academy of Family Practice, American
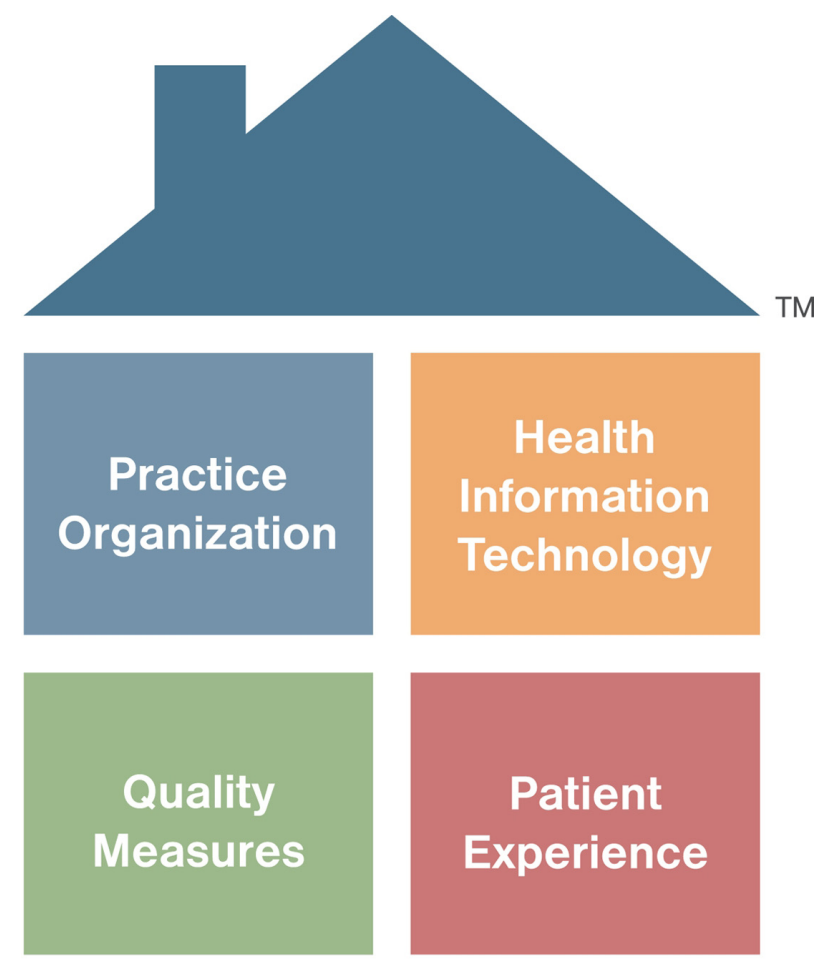

\section{Family Medicine}

Figure 2 The American Academy of Family Practice model of the Patient-Centered Medical Home.

Note: Used wth permission from American Academy of Family Practice www.aafp. org/pcmh. ${ }^{45}$
College of Physicians, American Academy of Pediatrics, and American Osteopathic Association, ${ }^{10}$ and their contents are summarized with COPD examples in Table 1. Elements scored in the 2011 standards and guidelines for Physician Practice Connections (PPC)-PCMH recognition evaluations are shown in Table $2 .{ }^{17}$ Although PPC-PCMH, like the joint principles, defines a PCMH as physician-led, the $\mathrm{PCMH}$ resource organization, TransforMED ${ }^{\mathrm{SM}}$, also recognizes $\mathrm{PCMH}$ practices led by physician assistants or nurse practitioners.

PCMH care is labor-intensive behind the scenes as well as in patient visits and should be compensated accordingly. Fee-for-service excludes nonvisit work and encourages overuse. Salary alone does not reward productivity, pure capitation encourages underuse, and pay for performance may shortchange unmetricated care. The American College of Physicians ${ }^{18}$ therefore advocates blended payment that retains visit-based fee-for-service payments and adds prospective, bundled payments for the structural overhead of $\mathrm{PCMH}$ practices and for care-coordinating "desktop medicine" activities. ${ }^{13}$ The final component is pay for performance, thus rewarding quality and efficiency goals.

Group Health Cooperative of Puget Sound conducted a 12-month quasi-experimental study comparing a designated PCMH practice with usual care clinics. ${ }^{13}$ Prior to the study, electronic health records and same-day scheduling had been adopted systemwide. The PCMH demonstration clinic reduced clinicians' case loads from about 2300 to 1800 patients, increased standard visits from 20 to 30 minutes, provided protected "desktop medicine" time, and altered the staff mix, raising physician assistant staffing levels by $44 \%$, registered nurses by $17 \%$, medical assistants and licensed practical nurses by $18 \%$, and clinical pharmacists by $72 \% .{ }^{13}$ At the end of 12 months, PCMH patients had 29\% fewer emergency room/urgent care visits and $11 \%$ fewer hospitalizations for ambulatory care sensitive conditions (including COPD) than usual care patients. Overall costs were unchanged between the $\mathrm{PCMH}$ and usual care, staff burnout levels were significantly reduced, and quality indicators improved significantly more in the PCMH than in usual care. ${ }^{13}$ The Group Health experience exemplifies the importance of multidisciplinary contributions to PCMH success.

\section{Contributions of physician assistants and nurse practitioners}

Physician assistants and nurse practitioners play important roles in PCMH transformation of practices and development of team care workflows for COPD management. They can help change care culture from reactive to proactive, combat therapeutic pessimism, and design and implement COPD 
Table I TransforMED PCMH Principles (http://www.transformed.com/pdf/TransforMEDMedicalHomeModel-letter.pdf) and their potential applications to COPD

PCMH concepts COPD applications

\section{Access to care and information}

- Same-day appointments

- After-hours access coverage

- Accessible patient and lab information

- Online patient services

- Electronic visits

- Group visits

\section{Practice-based services}

- Comprehensive care for acute and chronic conditions

- Prevention screening and services

- Ancillary therapeutic and support services

- Ancillary diagnostic services

\section{Care management}

- Population management

- Wellness promotion

- Disease prevention

- Patient engagement and education

- Leverage of automated technologies

Care coordination

- Community-based resources

- Collaborative relationships with hospitals, ERs, specialists, pharmacies, physical therapy, case management

- Care transition

\section{Practice-based care team}

- Clinician-led multidisciplinary team

- Shared mission and vision

- Effective communication

- Task designation by skill set

- NP/PA

- Patient participation

- Family involvement options

Quality and safety

- Evidence-based best practices

- Medication management

- Patient satisfaction feedback

- Clinical outcomes analysis

- Quality improvement

- Risk management

- Regulatory compliance

Health information technology

- Electronic medical record

- Electronic orders and reporting

- Electronic prescribing

- Evidence-based decision support

- Population management registry

- Practice web site

- Patient portal

\section{Practice management}

- Disciplined financial management

- Cost-benefit decision making

- Revenue enhancement

- Optimized coding and billing
- Same-day appointments and after-hours access may facilitate timely primary care of acute exacerbations

- Online services and electronic visits provide professional guidance for COPD self-management (particularly helpful for homebound or less-mobile patients)

- Group visits offer an efficient and interactive format for planned care and patient education

- Team division of labor could facilitate planned COPD care

- Practice-based preventive services should include smoking cessation assistance

- Practice-based spirometric testing can be provided by a trained PA, NP, RRT, or RN

- COPD patient registry could facilitate management of practice's COPD population - Patient education is key to coping with COPD

- Practices can connect COPD patients with community stop-smoking support groups, gyms, American Lung Association chapters/Better Breathers' clubs

- Continuity of care needs to be maintained when patient returns to PCP after an exacerbation managed in the hospital or ER

- Pulmonologist referral should be arranged and coordinated when needed

- Parallel primary/specialty care rather than gatekeeping is the PCMH norm

- Referral to pulmonary rehabilitation and access to exercise after formal rehab can be coordinated by the practice

- PAs and NPs can play essential roles in team care of COPD

- If patients wish, interested caregivers/partners/relatives may be invited to COPD group visits along with patients

- Prompts based on COPD guidelines (spirometry, immunization, long-acting bronchodilation) could be built into clinical information systems

- Clinical outcomes to analyze could include receipt of spirometry, exacerbation rates, and time between exacerbation-related hospital discharge and PCP follow-up

- Administrative data should be checked and curated carefully before being used for clinical registry purposes!

- The Devon Primary Care Audit tested a COPD assessment software tool usable on electronic medical record data

- Change management is particularly central to the success of a PCMH transition

- Proper coding facilitates reimbursement for primary care spirometry and group COPD visits 
Table I (Continued)

PCMH concepts COPD applications

- Personnel/human resource management

- Facilities management

- Blended payment model avoids the drawbacks of major models: salary alone

- Optimized office design/redesign (disincentive to productivity), fee for service (incentive to overuse), capitation (incentive to underuse) or pay for performance (disincentive for unmeasured aspects of care)

- Change management

Abbreviations: COPD, chronic obstructive pulmonary disease; ER, emergency room; NP, nurse practitioner; PA, physician assistant; PCMH, Patient-Centered Medical Home; PCP, primary care provider; RN, registered nurse; RRT, registered respiratory therapist.

Note: Used with permission from TransforMED LLC. TransforMED ${ }^{S M}$ PCMH Principles as adapted from The TransforMED Patient-Centered Model at http://www. TransforMED.com/pdf/TransforMEDMedicalHomeModel-letter.pdf and their potential applications to COPD.

care processes. Physician assistants and nurse practitioners at the first-line primary care interface can combat patients' denial of COPD, encourage smoking cessation, institute maintenance treatment, and enable self-management. PCMH team members collaborating with patients can develop concordant care plans, making it easier for the patient to persevere with a smoke-free, active lifestyle and to remain on appropriate medication.

Chronic care for COPD should strive to reduce the risk of exacerbations and delay their onset to reduce health care burden and improve health-related quality of life. The elements of primary care COPD management include smoking cessation, immunizations, physical activity, pulmonary rehabilitation (if dyspnea and functional disability are present), acute care of exacerbations arising, and maintenance pharmacotherapy to reduce exacerbations. ${ }^{1}$

Smoking cessation, especially before the age of 40-45 years, slows loss of lung function in COPD to a rate usual for age. ${ }^{19}$ Evidence-based smoking cessation assistance should be offered to patients choosing to quit. ${ }^{1,20}$

Major COPD guidelines recommend that maintenance treatment with long-acting inhaled anticholinergic or $\beta$-adrenergic agents begin no later than moderate COPD. ${ }^{1}$ Maintenance treatment of COPD may reduce severity of symptoms, reduce exacerbations, maintain activity, and improve health-related quality of life. Tiotropium is approved by the US Food and Drug Administration (FDA) for maintenance treatment of bronchospasm associated with COPD and to reduce exacerbations in COPD patients; salmeterol/fluticasone is also approved by the FDA for maintenance treatment of airway obstruction in COPD and to reduce exacerbations in COPD patients with a history of exacerbations. Budesonide/formoterol is approved by the FDA for maintenance treatment of airway obstruction in COPD but does not have an approved indication to reduce exacerbations. Oral roflumilast received FDA approval on March 1, 2011 to reduce the risk of exacerbations of COPD in patients with severe COPD associated with chronic bronchitis and a history of exacerbations (http://www.fda.gov/NewsEvents/Newsroom/ PressAnnouncements/ucm244989.htm; http://www.frx.com/ news/PressRelease.aspx?ID=1534051). The Global Initiative for Chronic Obstructive Lung Disease (GOLD) guidelines of 2010 state that roflumilast may be combined with long-acting bronchodilators. ${ }^{1}$ Maintenance therapies that have been shown to improve exercise parameters in patients with COPD include tiotropium, ${ }^{21}$ salmeterol/fluticasone, ${ }^{22}$ combined tiotropium and salmeterol/fluticasone, ${ }^{23}$ combined tiotropium and formoterol, ${ }^{24}$ budesonide/formoterol, ${ }^{25}$ salmeterol alone, ${ }^{26}$ or formoterol alone. ${ }^{27}$ Improving patients' capacity for physical activity may enhance both pulmonary rehabilitation and valued life activities. Care team members can connect COPD patients with pulmonary rehabilitation and encourage routine physical activity, forestalling progressive deconditioning and worsening dyspnea. ${ }^{28}$

PCMH team members, including physician assistants, nurse practitioners, registered respiratory therapists, and/or designated and specially trained health coaches ${ }^{29}$ (who may be nurses, medical assistants, or health educators), can teach and empower patients to self-manage COPD between office visits. Exacerbation self-management action plans (such as the Canadian Thoracic Society plan available online at http:// www.lung.ca/pdf/1408_THOR_ActionPlan_v3.pdf) can help patients recognize and medicate exacerbations promptly and discern when to visit the primary care clinic or emergency room. Self-management support reduces health care utilization in COPD. Provision of one education session, an exacerbation action plan, and a monthly telephone follow-up to US veterans with severe COPD reduced COPD-related hospitalizations/emergency room visits by $41 \% .^{30}$

\section{PCMH-based solutions to challenges in COPD management}

PCMH methods provide multiple ways to improve COPD care (Table 2), where "practice as usual" has encountered challenges. Continuous healing relationships for wholeperson care can change episodic, reactive, and emergent COPD care into planned ongoing proactive management. In current practice, COPD care is often driven by exacerbation emergencies, ${ }^{31}$ with acute non-respiratory problems and multiple comorbidities taking primary care physician visit 
Table 2 Practice components evaluated for PPC-PCMH recognition ${ }^{17}$

\begin{tabular}{ll}
\hline Domain & Must-pass element \\
\hline Access and continuity & IA documented processes to provide same-day \\
& appointments, timely clinical advice by \\
telephone/secure email, and to document & clinical advice in the medical record
\end{tabular}

Additional/advanced element

IB documented processes to provide after-hours access to appointments, records, and documentable clinical advice

IC secure electronic systems for patients to access current health records, communicate with the practice, request appointments/refills/referrals

ID continuity: documented patient selection of personal clinician and preponderance of visits with that person or team

IE informing patients about PCMH role

IF assessing and meeting cultural and linguistic needs of patient population

IG practice team organization: defined roles; meetings/ communications; standing orders; distribution of tasks for patient care, self-management support, population management, and communication; involving teams in quality improvement
Identifying and managing patient populations

Planning and managing care

Providing self-care and community support

Tracking and coordinating care

Measuring and improving performance
2D using data for population management of preventive and chronic care services, patients not recently seen, and specific medications

3C care management: previsit preparation, collaborative written care plan, addressing barriers to treatment goals, visit summary, identification of patients needing additional support; follow-up with patients who miss important visits

4A self-care process: education, tools, counseling; collaborative, documented self-management plan $5 \mathrm{~B}$ referral tracking and follow-up
2A electronic, structured, searchable patient information

2B electronic, structured, searchable clinical data $2 \mathrm{C}$ documented comprehensive health assessment: immunizations/screenings, history, advance planning, health behaviors, mental health, substance abuse, depression screening

3A implementing evidence-based guidelines for three important conditions (including one unhealthful behavior or mental health/substance abuse problem) 3B identifying high-risk or complex patients 3D managing medications: reconciliation across transitions, prescription information, response and adherence assessment

3 E electronic generation and transmission of prescriptions, integrated with patient records and patient-specific interaction/allergy warnings 4B community resource referrals specific to the practice population's needs; provision or arrangement of behavioral health treatment

$5 \mathrm{~A}$ test tracking, follow-up, flagging of abnormalities, and patient notification

5C coordination with facilities/care transitions: identification and follow-up care of patients with hospitalizations/emergency visits, exchanging information with/receiving discharge summaries from hospitals; written plan for pediatric-adult care transition

6C implementing continuous quality improvement for care performance, patient experience, and disparity reduction
6A measures of performance: preventive and chronic or acute care, cost/utilization, disparities 6B feedback on patient/family experience 6D demonstrating continuous quality improvement by results tracked over time

$6 \mathrm{E}$ performance reporting within the practice (individual and aggregate) and to patients or the public 6F external data reporting: ambulatory clinical quality measures to Center for Medicare/Medicaid Services, immunization data to registries, syndrome surveillance to public health agencies 
time away from COPD concerns. ${ }^{11}$ Scheduled well-care visits (eg, every four months) devoted to COPD maintenance are a potential PCMH solution. ${ }^{32}$ Some practices that conduct wellcare COPD visits find that patients spontaneously evolve into an informal peer support group.

Access to care and information can reduce COPD-related emergency room use and help patients and families cope. Prompt primary care of exacerbations improves outcomes, yet is difficult to achieve in current practice. Direct emergency room visits for exacerbations are sometimes the initial presentation of undiagnosed and unaware COPD patients. ${ }^{31,33}$ Emergency room visits may result from after-hours acute events but also from patients' difficulty in scheduling prompt primary care physician visits. Advanced access to sameday primary care in COPD chronic care programs reduces inpatient and emergency room utilization. ${ }^{34}$ Group visits, which is another PCMH emphasis, allow interactive and efficient COPD maintenance and patient education. Nurse practitioners or physician assistants can effectively conduct group visits, ${ }^{35}$ and registered respiratory therapists can teach inhaler technique for any stage of COPD and proper longterm oxygen use for hypoxemic severe COPD. Diabetes care has a well developed group visit methodology; ${ }^{36}$ but COPD group visit models need further research.

Practice-based services and care management in the PCMH can integrate COPD diagnosis and treatment resources. In current practice, COPD diagnosis is often recorded without performing spirometry, ${ }^{37}$ maintenance treatment is underused, and adherence and persistence are insufficiently monitored. ${ }^{38}$ More newly diagnosed COPD patients received primary care physician practice-based spirometry in the Group Health Cooperative PCMH demonstration clinic than in usual care clinics. ${ }^{13}$ Practice-based spirometry also may help reduce tobacco use and COPD progression; smokers who learn that they have spirometric airway obstruction are more likely to quit. ${ }^{39}$ Chronic disease patient registries help a practice to improve the health of its COPD patient population. ${ }^{40}$ Healthcare Effectiveness Data and Information Set indicators applicable to COPD care may be appropriate for within-practice tracking as well as public reporting. Additional registry contents may include exacerbation rates, primary care physician follow-up after exacerbations, prescription refill rates, activity levels, employment/ retirement status, and household members.

Care coordination and electronic communication can improve care transitions. If primary care providers remain unaware when their own patients are hospitalized for exacerbations, maintenance treatment may not be restarted at discharge, ${ }^{41}$ heightening the risk of recurrent exacerbations. ${ }^{42,43}$ In addition, lung function test results or pulmonologists' reports may not promptly reach all primary care team members. A recent evaluation showed that Group Health Cooperative PCMH patients were 1.89 times more likely than usual care patients to receive a call or secure email from a primary care physician within three days of hospital or emergency room discharge. ${ }^{13}$

Practice-based care teams can consciously assign COPD management tasks (smoking cessation support, inhaler technique instruction, and adherence monitoring) to specific members of the care team so that nothing needful is omitted. In a successful PCMH workflow, the division of tasks depends on individual skill sets rather than on rigid job descriptions, and every team member works at his or her highest licensed level of care.

Quality and safety systems, including meaningful electronic health records use and evidence-based decision support, are central to the PCMH. In current practice, guidelines are often not followed, ${ }^{2}$ and patients on maintenance treatment may be insufficiently followed up regarding adherence. ${ }^{38}$ Guideline-based COPD care ${ }^{1}$ includes diagnostic postbronchodilator spirometry, short-acting bronchodilators, maintenance treatment, and pulmonary rehabilitation beginning at moderate COPD, and influenza and pneumonia vaccinations. Electronic reminders help clinicians implement guidelines, and electronic prescribing can track patient medication use, adherence, and potential drug interactions. An electronic COPD registry can track exacerbation rates to reduce them over time. Electronic health records, electronic prescribing, and guideline reminders are required for tiers 2 and 3 of PPC-PCMH certification. Publicly reportable Healthcare Effectiveness Data and Information Set indicators relevant to COPD are shown in Table 3.

Practice management patterns in the PCMH emphasize planned, coordinated, and reflective chronic care, in contrast with current practice focusing on acute care episodes and payment for procedures. ${ }^{8}$ In a fee-for-service system, lack of payment for care coordination and registry-related tasks is a disincentive to expend energy on them..$^{18} \mathrm{PCMH}$ payment structures should reflect the value of PCMH care planning and management (Table 2). The accountable care organization approach includes specialty, inpatient, and emergency room services in an integrated and electronically interoperable patient-centered medical village, sharing in the Medicare savings it generates by coordinating care rather than driving 
Table 3 Healthcare Effectiveness Data and Information set 20 I I indicators relevant to COPD care

\begin{tabular}{|c|c|}
\hline Domain & Indicator \\
\hline $\begin{array}{l}\text { COPD-specific care } \\
\text { measurements }\end{array}$ & $\begin{array}{l}\text { Use of spirometry in the assessment and } \\
\text { diagnosis of COPD } \\
\text { Pharmacotherapy of acute exacerbations } \\
\text { Relative resource use by COPD patients }\end{array}$ \\
\hline $\begin{array}{l}\text { General preventive care } \\
\text { measurements of special } \\
\text { importance in COPD }\end{array}$ & $\begin{array}{l}\text { Medical tobacco cessation assistance } \\
\text { Influenza vaccinations for patients aged } \\
50-64 \text { years (reported for commercial } \\
\text { health plans) and those } 65+\text { years } \\
\text { (reported for Medicare) } \\
\text { Pneumonia vaccinations for patients } \\
\text { aged } 65+\text { years (reported for Medicare) }\end{array}$ \\
\hline $\begin{array}{l}\text { Medication monitoring } \\
\text { and reconciliation }\end{array}$ & $\begin{array}{l}\text { Annual monitoring of persistent } \\
\text { medications } \\
\text { Medication reconciliation after hospital } \\
\text { discharge }\end{array}$ \\
\hline
\end{tabular}

Note: Data from http://www.ncqa.org/Portals/0/HEDISQM/HEDIS\%2020I I/HEDIS\%20 $2011 \% 20$ Measures.pdf. ${ }^{46}$

supply-sensitive utilization. ${ }^{8,15,44}$ Optimizing payment models for PCMH care patterns provides an economically viable and sustainable practice.

\section{Conclusion}

The PCMH model has the potential to improve outcomes in chronic diseases, such as COPD, by shifting the primary care focus from acute rescue to proactive maintenance and by shifting practice culture from maximizing reimbursable specialty procedures to maintaining coordinated, reflective, and accountable chronic disease care. PCMH-based multidisciplinary redesign of the COPD care workflow offers new approaches to primary care and patient education that will contribute critically to improving patient outcomes and controlling costs in a sustainable health care system.

\section{Acknowledgment}

This article was developed on the basis of presentations and discussions by the authors at the Overcoming Barriers to COPD Identification and Management task force meeting in New York, NY, March 22-23, 2009. This meeting, author participation, and manuscript preparation were supported by funding from Boehringer-Ingelheim Pharmaceuticals Inc. Writing and editorial assistance was provided by Kim Coleman Healy, of Envision Scientific Solutions, which was contracted by BIPI for these services. The authors meet criteria for authorship as recommended by the International Committee of Medical Journal Editors (ICMJE), were fully responsible for all content and editorial decisions, and were involved at all stages of review article development. The authors received no compensation related to the development of the review article. The article reflects the concepts of the authors and is their sole responsibility. It was not reviewed by BIPI and Pfizer Inc, except to ensure medical and safety accuracy.

\section{Disclosure}

GO has been a consultant to Boehringer-Ingelheim Pharmaceuticals Inc, CSL Behring, Pfizer, Sanofi-Aventis, Schering-Plough/Merck, Sepracor, and TEVA, and currently serves as a consultant for Dey, Merck, Sunovion, and TEVA, and is a speakers' bureau member for Phadia AS, Merck, and TEVA. LF has received speakers' bureau honoraria from Boehringer-Ingelheim Inc and Pfizer and is a member of the board of TransforMED, LLC; a not for profit subsidiary of the American Academy of Family Practice.

\section{References}

1. Global Initiative for Chronic Obstructive Lung Disease. Global Strategy for the Diagnosis, Management and Prevention of COPD. December 2010; http://www.goldcopd.com/Guidelineitem. asp?11=2\&12=1\&intId=989. Accessed March 14, 2011.

2. Mularski RA, Asch SM, Shrank WH, et al. The quality of obstructive lung disease care for adults in the United States as measured by adherence to recommended processes. Chest. 2006;130(6):1844-1850.

3. Gawande A. The cost conundrum. New Yorker. June 1, 2009.

4. Fisher ES, Wennberg DE, Stukel TA, Gottlieb DJ, Lucas FL, Pinder EL. The implications of regional variations in Medicare spending. Part 2: health outcomes and satisfaction with care. Ann Intern Med. 2003;138(4):288-298.

5. Blue Ribbon Panel of the Society of General Internal Medicine. Redesigning the practice model for general internal medicine. A proposal for coordinated care: a policy monograph of the Society of General Internal Medicine. J Gen Intern Med. 2007;22(3):400-409.

6. Institute of Medicine. Crossing the quality chasm: a new health system for the 21st century. Washington, DC: National Academy Press; 2001.

7. Mirabito AM, Berry LL. Lessons that patient-centered medical homes can learn from the mistakes of HMOs. Ann Intern Med. 2010;152(3):182-185.

8. Rittenhouse DR, Shortell SM, Fisher ES. Primary care and accountable care - two essential elements of delivery-system reform. N Engl J Med. 2009;361(24):2301-2303.

9. Wagner EH. Chronic disease management: what will it take to improve care for chronic illness? Eff Clin Pract. 1998;1(1):2-4.

10. American Academy of Family Physicians. Joint principles of the Patient-Centered Medical Home. Del Med J. 2008;80(1):21-22.

11. Bodenheimer $\mathrm{T}$, Wagner $\mathrm{EH}$, Grumbach $\mathrm{K}$. Improving primary care for patients with chronic illness. JAMA. 2002;288(14):1775-1779.

12. Yarnall KS, Ostbye T, Krause KM, Pollak KI, Gradison M, Michener JL. Family physicians as team leaders: "time" to share the care. Prev Chronic Dis. 2009;6(2):A59.

13. Reid RJ, Fishman PA, Yu O, et al. Patient-centered medical home demonstration: a prospective, quasi-experimental, before and after evaluation. Am J Manag Care. 2009;15(9):e71-e87.

14. Nutting PA, Miller WL, Crabtree BF, Jaen CR, Stewart EE, Stange KC. Initial lessons from the first national demonstration project on practice transformation to a patient-centered medical home. Ann Fam Med. 2009;7(3):254-260. 
15. Fisher ES, McClellan MB, Bertko J, et al. Fostering accountable health care: moving forward in Medicare. Health Aff (Millwood). 2009;28(2):w219-w231.

16. Bindman AB, Chattopadhyay A, Auerback GM. Interruptions in Medicaid coverage and risk for hospitalization for ambulatory caresensitive conditions. Ann Intern Med. 2008;149(12):854-860.

17. National Committee for Quality Assurance. PCMH 2011 Standards Washington, DC: National Committee for Quality Assurance; 2011.

18. American College of Physicians. A System in Need of Change: Restructuring Payment Policies to Support Patient-Centered Care. [PositionPaper]. Philadelphia, PA: American College of Physicians; 2006.

19. Young RP, Hopkins R, Eaton TE. Forced expiratory volume in one second: not just a lung function test but a marker of premature death from all causes. Eur Respir J. 2007;30(4):616-622.

20. Radin A, Cote C. Primary care of the patient with chronic obstructive pulmonary disease - part 1: frontline prevention and early diagnosis. Am J Med. 2008;121(7 Suppl):S3-S12.

21. Maltais F, Hamilton A, Marciniuk D, et al. Improvements in symptomlimited exercise performance over $8 \mathrm{~h}$ with once-daily tiotropium in patients with COPD. Chest. 2005;128(3):1168-1178.

22. O'Donnell DE, Sciurba F, Celli B, et al. Effect of fluticasone propionate/ salmeterol on lung hyperinflation and exercise endurance in COPD Chest. 2006;130(3):647-656.

23. Pasqua F, Biscione G, Crigna G, Auciello L, Cazzola M. Combining triple therapy and pulmonary rehabilitation in patients with advanced COPD: a pilot study. Respir Med. 2010;104(3):412-417.

24. Berton DC, Reis M, Siqueira AC, et al. Effects of tiotropium and formoterol on dynamic hyperinflation and exercise endurance in COPD. Respir Med. 2010;104(9):1288-1296.

25. Worth H, Forster K, Eriksson G, Nihlen U, Peterson S, Magnussen H. Budesonide added to formoterol contributes to improved exercise tolerance in patients with COPD. Respir Med. 2010;104(10):1450-1459.

26. O'Donnell DE, Voduc N, Fitzpatrick M, Webb KA. Effect of salmeterol on the ventilatory response to exercise in chronic obstructive pulmonary disease. Eur Respir J. 2004;24(1):86-94.

27. Neder JA, Fuld JP, Overend T, et al. Effects of formoterol on exercise tolerance in severely disabled patients with COPD. Respir Med. 2007;101(10):2056-2064.

28. Pitta F, Troosters T, Probst VS, Langer D, Decramer M, Gosselink R. Are patients with COPD more active after pulmonary rehabilitation? Chest. 2008;134(2):273-280.

29. Bodenheimer T, Laing BY. The teamlet model of primary care. Ann Fam Med. 2007;5(5):457-461.

30. Rice KL, Dewan N, Bloomfield HE, et al. Disease management program for chronic obstructive pulmonary disease: a randomized controlled trial. Am J Respir Crit Care Med. 2010;182(7):890-896.

31. Zoia MC, Corsico AG, Beccaria M, et al. Exacerbations as a starting point of pro-active chronic obstructive pulmonary disease management. Respir Med. 2005;99(12):1568-1575.

32. Bodenheimer T. Planned visits to help patients self-manage chronic conditions. Am Fam Physician. 2005;72(8):1454-1456.
33. Bastin AJ, Starling L, Ahmed R, et al. High prevalence of undiagnosed and severe chronic obstructive pulmonary disease at first hospital admission with acute exacerbation. Chron Respir Dis. 2010;7(2):91-97.

34. Adams SG, Smith PK, Allan PF, Anzueto A, Pugh JA, Cornell JE. Systematic review of the chronic care model in chronic obstructive pulmonary disease prevention and management. Arch Intern Med. 2007;167(6):551-561.

35. Watts SA, Gee J, O’Day ME, et al. Nurse practitioner-led multidisciplinary teams to improve chronic illness care: the unique strengths of nurse practitioners applied to shared medical appointments/group visits. J Am Acad Nurse Pract. 2009;21(3):167-172.

36. Kirsh S, Watts S, Pascuzzi K, et al. Shared medical appointments based on the chronic care model: a quality improvement project to address the challenges of patients with diabetes with high cardiovascular risk. Qual Saf Health Care. 2007;16(5):349-353.

37. Walker PP, Mitchell P, Diamantea F, Warburton CJ, Davies L. Effect of primary-care spirometry on the diagnosis and management of COPD. Eur Respir J. 2006;28(5):945-952.

38. Restrepo RD, Alvarez MT, Wittnebel LD, et al. Medication adherence issues in patients treated for COPD. Int J Chron Obstruct Pulmon Dis. 2008;3(3):371-384.

39. Parkes G, Greenhalgh T, Griffin M, Dent R. Effect on smoking quit rate of telling patients their lung age: the Step 2 quit randomised controlled trial. BMJ. 2008;336(7644):598-600.

40. Jones RC, Dickson-Spillmann M, Mather MJ, Marks D, Shackell BS. Accuracy of diagnostic registers and management of chronic obstructive pulmonary disease: the Devon primary care audit. Respir Res. 2008;9:62.

41. Drescher GS, Carnathan BJ, Imus S, Colice GL. Incorporating tiotropium into a respiratory therapist-directed bronchodilator protocol for managing in-patients with COPD exacerbations decreases bronchodilator costs. Respir Care. 2008;53(12):1678-1684.

42. Hurst JR, Donaldson GC, Quint JK, Goldring JJ, Baghai-Ravary R, Wedzicha JA. Temporal clustering of exacerbations in chronic obstructive pulmonary disease. Am J Respir Crit Care Med. 2009;179(5): 369-374.

43. McGhan R, Radcliff T, Fish R, Sutherland ER, Welsh C, Make B. Predictors of rehospitalization and death after a severe exacerbation of COPD. Chest. 2007;132(6):1748-1755.

44. Fisher ES, Wennberg JE. Health care quality, geographic variations, and the challenge of supply-sensitive care. Perspect Biol Med. 2003;46(1):69-79.

45. American Academy of Family Practice. Patient-Centered Medical Home (PCMH). Available from: http://www.aafp.org/online/en/home/ membership/initiatives/pcmh.html. Accessed September 29, 2011.

46. National Committee for Quality Assurance. HEDIS 2011 Summary Table of Measures, Product Lines and Changes. Available from: http:// www.ncqa.org/Portals/0/HEDISQM/HEDIS\%202011/HEDIS\%20 2011\%20Measures.pdf. Accessed September 29, 2011.

\section{Dovepress}

\section{Publish your work in this journal}

The Journal of Multidisciplinary Healthcare is an international, peerreviewed open-access journal that aims to represent and publish research in healthcare areas delivered by practitioners of different disciplines. This includes studies and reviews conducted by multidisciplinary teams as well as research which evaluates the results or conduct of such teams or healthcare processes in general. The journal covers a wide range of areas and welcomes submission from practitioners at all levels, from all over the world. The manuscript management system is completely online and includes a very quick and fair peer-review system. Visit http://www.dovepress.com/testimonials.php to read real quotes from published authors. 